\title{
Treatment Satisfaction with Insulin Glargine in Insulin-Naïve Type 2 Diabetes Patients-A Hong Kong Based Registry
}

\author{
Wing-Bun Chan', Wilson W. M. Ngai², Peter Chun-Yip Tong1 \\ ${ }^{1}$ Department of Medicine and Therapeutics, Chinese University of Hong Kong, Hong Kong, China \\ ${ }^{2}$ Sanofi-Aventis (Hong Kong) Limited, Hong Kong, China \\ Email: wingbun.chan@gmail.com
}

Received 18 June 2014; revised 15 July 2014; accepted 8 August 2014

Copyright (C) 2014 by authors and Scientific Research Publishing Inc.

This work is licensed under the Creative Commons Attribution International License (CC BY). http://creativecommons.org/licenses/by/4.0/

(c) (i) Open Access

\section{Abstract}

Objective: To evaluate patient satisfaction with insulin glargine. Design: Multicentre observational registry. Data were collected at baseline/inclusion visit, and 12 and 24 weeks. Setting: Physicians in Hong Kong, who managed type 2 diabetes patients and had $>5$ years' experience in using insulin glargine. Patients: People with type 2 diabetes, new to insulin, aged 18 - 75 years, who were previously being treated with $\leq 3$ oral antidiabetes drugs (OAD) and had HbA1c $>7 \%$, and in whom the physicians had chosen to prescribe glargine for the first time. Main outcome measures: Treatment satisfaction assessed by Diabetes Treatment Satisfaction Questionnaire (DTSQs), glycaemic control (fasting blood glucose and HbA1c) and adverse events. Results: Between April 2010-0ctober 2011, 41 patients completed the study. Average duration of diabetes and OAD therapy was $7.8 \pm$ 8.0 years and $6.7 \pm 7.4$ years, respectively. The global DTSQs treatment satisfaction scores improved from 20.9 at baseline to $28.4(p<0.05)$ at the end of 24 weeks insulin glargine treatment. Analysis of DTSQs scores showed a decrease in perceived frequency of hyperglycaemia (4.1 to 1.9, $\mathrm{p}<0.001)$ and hypoglycemia $(2.2$ to $1.5, \mathrm{p}=0.079)$. Perceived convenience $(0.60, \mathrm{p}<0.025)$ and flexibility $(0.9, p<0.009)$ were also improved from baseline. Reduction in mean HbA1c $(10.2 \% \pm$ $2.2 \%$ to $7.0 \% \pm 1.0 \%)$ and fasting blood glucose $(10.9 \pm 4.0 \mathrm{mmol} / \mathrm{L}$ to $6.4 \pm 1.8 \mathrm{mmol} / \mathrm{L})$ from baseline to study termination was significant $(p<0.05)$. Almost half $(48.7 \%)$ of patients achieved HbA1c $\leq 7.0 \%$, while $26.0 \%$ patients had FBG $<5.6$ mmol/L. In total, $9(22.0 \%)$ patients experienced at least one hypoglycemia event; there were no reports of severe hypoglycaemia. Conclusions: Despite a small number of subjects completed in this study, the study demonstrated clearly that the addition of insulin glargine to OAD therapy in diabetes management improved treatment satisfaction and perceived frequency of hyper-and hypoglycaemia together with glycaemic control close to recommended target without severe side-effects in this cohort of patients in Hong Kong. 


\section{Keywords}

\section{Insulin Glargine, Patient Satisfaction, Hong Kong, Type 2 Diabetes Mellitus}

\section{Introduction}

Type 2 diabetes mellitus (T2DM) is a chronic, progressive disease resulting in microvascular (retinopathy, neuropathy, and nephropathy) and macrovascular (coronary artery disease, peripheral arterial disease, and stroke) complications. The main goal in clinical management of T2DM is to achieve and maintain a good glycaemic control in order to delay the onset and progression of these complications [1]. Glycosylated haemoglobin (HbA1c) is a valuable marker for glycaemic control, and while various medical bodies have recommended somewhat different HbA1c targets, the most widely accepted is the American Diabetes Association definition of adequate glycaemic control as HbA1c $<7.0 \%$ [2] [3]. Despite these guidelines, a majority of T2DM patients are unable to achieve their HbA1c targets [4].

In early T2DM, glycaemic control can be reasonably attained by appropriate life style modifications and usage of oral antidiabetes (OAD) therapy [5]. However, given the progressive destruction of pancreatic islet cells over time in T2DM, a majority of T2DM patients will eventually require exogenous insulin [6]. In fact, it has been shown that within 6 to 10 years of initial diagnosis with T2DM, about $60 \%$ of the patients will need insulin therapy in order to achieve reasonable glycaemic control [7] [8].

Despite the need for insulin treatment, numerous factors, both patient- and physician-related, prevent patients from receiving timely insulin treatment. About half of insulin-naïve patients with diabetes are either unwilling or somewhat willing to start insulin therapy [9]. This "psychological insulin resistance" stems from patient's concern about needles, potential weight gain and the fear of hypoglycaemia [10]. Furthermore, despite clinical data having shown the effectiveness of insulin in achieving glycaemic control, most physicians are reluctant to initiate insulin [10] [11].

Insulin glargine (Lantus Solostar ${ }^{\circledR}$ by Sanofi) is the first basal insulin analogue with no pronounced peak in activity and a 24-hour duration that requires only once daily administration [12]. In comparison with neutral protamine Hagedorn (NPH) insulin, an intermediate-acting insulin, insulin glargine has an equivalent effect on glycaemic control albeit with a lower incidence of hypoglycaemia [13]-[16]. Observations from the Canadian INSIGHT (Implement New Strategies with Insulin Glargine for Hyperglycaemia Treatment) trial showed an achievement of $\mathrm{HbA} 1 \mathrm{c}<6.5 \%$ and improved quality of life in insulin-naïve, poorly controlled patients when insulin glargine was added to their existing OAD regimen [17]. Thus, insulin glargine can be used as the insulin of choice for achieving tighter glycaemic control without the fear of hypoglycaemia. Moreover, insulin glargine can be and is prescribed in combination with OADs in T2DM patients when OAD therapy alone is ineffective in achieving target HbA1c levels [18] [19].

As the barrier to insulin treatment is often subject to cultural influence [10], we conducted this study to ascertain the impact of insulin glargine on patient treatment satisfaction in insulin-naïve T2DM Chinese patients in Hong Kong, who were unable to achieve glycaemic control on OAD therapy alone. We also intended to assess the effectiveness of glargine in achieving targeted HbA1c and fasting blood glucose (FBG) goals as well as the tolerability profile of glargine in our study patients.

\section{Methods}

\subsection{Study Design and Objectives}

The Glargine Registry on Treatment Satisfaction was a multicentre, prospective, observational study aimed to analyze the patient satisfaction of insulin glargine in insulin-naïve T2DM patients, who had been on OAD therapy, but had inadequate glycaemic control. The other study objectives were to evaluate the effectiveness and safety of glargine in these patients at 24 weeks after insulin glargine initiation. This registry was conducted in accordance with the guidelines for Good Epidemiology Practice and the principles were laid down by the 18th World Medical Assembly (Helsinki, 1964) and all its applicable amendments. 


\subsection{Physician and Patient Population}

Physicians, who were managing T2DM patients and having more than five years' experience in prescribing glargine, participated in this study. It was planned to recruit a total of 8 - 15 endocrinologists to carry out this study.

Study patients were recruited consecutively by each investigator. Enrolled patients were of either gender, aged 18 - 75 years, on OAD therapy with $\leq 3$ agents, with $\mathrm{HbAlc}>7 \%$ and had never been prescribed insulin therapy prior to enrolment. In addition, recruited patients had to be eligible for insulin therapy as per the physicians' judgement, be willing to self-perform regular blood glucose monitoring and filled in the Diabetes Treatment Satisfaction Questionnaire (DTSQs), and signed the data release consent. Those patients, who were treated previously with insulin or with $>3$ OAD agents; had participated in a clinical trial with any investigational drug within 30 days prior to study entry; were mentally disabled and were unable to understand or sign the data release consent; were unable to comply with follow-up visits; were pregnant or breastfeeding, were excluded from the study.

\subsection{Study Visits and Data Collection}

In addition to the baseline (recruitment) visit, patients had to visit the physician for two follow-up visits at 12 $( \pm 4)$ and $24( \pm 4)$ weeks after initiation of glargine therapy. Data collected included patient demographics and diabetes history (duration, therapy, HbA1c and FBG levels [within 4 weeks prior to baseline visit and within 2 weeks prior to follow-up visits], and risk factors). Patients were asked to complete a DTSQs form at baseline and at the end of the study. Data was also collected during the follow-up visits on incidences of hypoglycaemia and other adverse events, and reasons for discontinuation of insulin glargine, if any.

\subsection{Safety and Weight Assessment}

Safety was evaluated by reported incidents of hypoglycaemia and other adverse events. Hypoglycaemia was categorized as Grade 1 (symptoms only) if a patient had symptoms with a self-measured capillary glucose level of $56 \mathrm{mg} / \mathrm{dL}$ ( $3.1 \mathrm{mmol} / \mathrm{L}$ ) or more, Grade 2 (minor) if the patient had symptoms with a self-measured capillary glucose level of less than $56 \mathrm{mg} / \mathrm{dL}$ ( $3.1 \mathrm{mmol} / \mathrm{L}$ ), or Grade 3 (major) if third-party assistance was required. Weight was also evaluated at baseline, 12 weeks and 24 weeks after initiation of glargine therapy.

\subsection{Statistical Analysis and Sample Size Calculation}

All data recorded was analyzed in an explorative manner. The primary outcome variable of the change in DTSQs score from baseline to final follow-up was analysed by an ANOVA model that factored in the period and sequence effects. Continuous variables were presented as frequency, mean, median, standard deviation and extreme values while categorical variables were described by the frequencies of each modality. The defaulted study design does not have the follow-up data but the baseline characteristics of the discontinued patients were not statistically different from those who completed the study. Group comparison for continuous variables was done by repeated measure ANOVA (analysis of variance) or Kruskall-Wallis test while the same for categorical variables was done by paired t-test. All statistical analyses were performed at $5 \%$ significance using 2-sided tests or confidence intervals. Statistical analysis was performed using the SPSS software version 11.5 (IBM, New York, USA). The sample size was estimated based on LAPTOP results and an assumption of DTSQs score difference. Assuming a difference of DTSQs score between baseline and endpoint of 4, an alpha of 0.05, a standard deviation of 8.2 and a power of $80 \%$. A sample size of 35 was required. Considering a dropout rate of $35 \%$, at least 54 patients needed to be enrolled.

\section{Results}

\subsection{Patient Demographics and Diabetes History}

A total of 60 T2DM patients were recruited in the study during April 2010 to October 2011. Of these, 41 patients completed the study. Most of the patients who did not complete the study were lost to follow-up $(n=14)$. The reasons for the drop-outs were: protocol deviation $(n=1)$, need for prandial insulin $(n=1)$, non-compliance to insulin glargine $(\mathrm{n}=2)$ and others $(\mathrm{n}=1)$. 
About two-thirds of the registry was composed of men $(n=27)$ (Table 1$)$. The mean age of the cohort was $53.0( \pm 11.1)$ years and the average body weight was $65.5( \pm 11.5) \mathrm{kg}$. The average duration of diabetes was 7.5 $( \pm 8.0)$ years and duration on OAD therapy was $6.7( \pm 7.4)$ years. Most of the patients $(37 \%, \mathrm{n}=15)$ were on a combination of 2 OADs, and more than one-fifth $(22 \%, n=9)$ were taking 3 OADs; the average number of OADs per patient was 1.9. Fifteen percent $(n=6)$ were taking SU at baselin.

Over two-thirds (71\%) of the patients presented with cardiovascular risk factors and 34\% of the patients had already progressed to microvascular disease. The mean systolic and diastolic blood pressures were $132.6( \pm 19.7)$ $\mathrm{mmHg}$ and $76.8( \pm 11.2) \mathrm{mmHg}$, respectively. At the time of enrolment, the average HbA1c was $10.2( \pm 2.2) \%$ while the mean FBG values was $10.9( \pm 4.0) \mathrm{mmol} / \mathrm{L}$.

\subsection{Diabetes Treatment Satisfaction Questionnaire (DTSQs) Score}

The DTSQs score showed a positive change in treatment satisfaction with insulin glargine (Table 2). Statistically significant improvements were perceived for most items-satisfaction $(\mathrm{p}<0.001)$, understanding $(\mathrm{p}<$

Table 1. Patient demographics and diabetes characteristics at baseline, $n=41$.

\begin{tabular}{|c|c|c|}
\hline & $\begin{array}{c}\text { Baseline } \\
\text { n (\%)/mean (SD) }\end{array}$ & $\begin{array}{c}24 \text { weeks } \\
\text { n (\%)/mean (SD) }\end{array}$ \\
\hline \multicolumn{3}{|l|}{ Gender } \\
\hline Men & \multicolumn{2}{|c|}{27 (65.9) } \\
\hline Women & \multicolumn{2}{|c|}{$14(34.1)$} \\
\hline Age, in years & \multicolumn{2}{|c|}{$53.0(11.1)$} \\
\hline Diabetes duration, in years & \multicolumn{2}{|c|}{$7.8(8.0)$} \\
\hline $\mathrm{OAD}$ duration, in years & \multicolumn{2}{|c|}{$6.7(7.4)$} \\
\hline Presence of microvascular disease ${ }^{*}$ & \multicolumn{2}{|c|}{$34 \%$} \\
\hline Presence of CV risk factors ${ }^{* *}$ & \multicolumn{2}{|c|}{$71 \%$} \\
\hline Body weight, in kilograms & $65.5(11.5)$ & $67.6(11.6)$ \\
\hline Average number of OADs & 2.0 & 1.7 \\
\hline HbA1c, in \% & $10.2(2.2)$ & $7.0(1.2)$ \\
\hline $\mathrm{FBG}$, in $\mathrm{mmol} / \mathrm{L}$ & $10.9(4.0)$ & $6.4(1.8)$ \\
\hline Systolic blood pressure, in mmHg & $132.6(19.7)$ & $130(14.2)$ \\
\hline Diastolic blood pressure, in mmHg & $76.8(11.2)$ & $77.7(11.1)$ \\
\hline
\end{tabular}

*Diabetic retinopathy, neuropathy and nephropathy; ${ }^{* *}$ Hypertension and hypercholesterolemia.

Table 2. Patient treatment satisfaction measured by the Diabetes Treatment Satisfaction Questionnaire status version (DTSQs): item and scale scores.

\begin{tabular}{|c|c|c|c|c|}
\hline \multirow{2}{*}{ Item \& scale scores } & \multicolumn{2}{|c|}{ DTSQs score } & \multirow{2}{*}{$\begin{array}{l}\text { Mean changes from baseline to endpoint } \\
\text { within treatment groups (SD) }\end{array}$} & \multirow{2}{*}{ p-value } \\
\hline & Baseline & 24 weeks & & \\
\hline 1. Satisfaction & 3.6 & 5.0 & $1.5(1.7)$ & $<0.001$ \\
\hline 4. Convenience & 3.9 & 4.5 & $0.6(1.6)$ & 0.025 \\
\hline 5. Flexibility & 3.3 & 4.2 & $0.9(2.0)$ & 0.009 \\
\hline 6. Understanding & 3.3 & 4.6 & $1.3(2.0)$ & $<0.001$ \\
\hline 7. Recommend to others & 3.7 & 5.1 & $1.4(2.0)$ & $<0.001$ \\
\hline 8. Wish to continue & 3.1 & 5.0 & $2.0(1.7)$ & $<0.001$ \\
\hline DTSQs scale score & 20.9 & 28.4 & $7.5(1.8)$ & $<0.001$ \\
\hline $\begin{array}{l}\text { 2. Perceived frequency } \\
\text { of hyperglycemia }\end{array}$ & 4.1 & 1.9 & $-2.3(2.4)$ & $<0.05$ \\
\hline $\begin{array}{l}\text { 3. Perceived frequency } \\
\text { of hypoglycemia }\end{array}$ & 2.2 & 1.5 & $-0.7(2.55)$ & 0.079 \\
\hline
\end{tabular}

DTSQ items 1 to 8 are scored from 6 (e.g. very satisfied, convenient etc.) to 0 (very dissatisfied, inconvenient, etc.); DTSQs scale score-combined score of items 1, 4, 5, 6, 7 and 8 . 
$0.001)$, recommend glargine to other patients with diabetes $(\mathrm{p}<0.001)$, and a wish to continue glargine $(\mathrm{p}<$ $0.001)$. The overall mean change in DTSQs scale score from baseline to the end of the study was $7.5( \pm 1.8)$ units $(\mathrm{p}<0.001)$ on the scale of $0-36$. With regards to patient perceived frequency of hyper- and hypo-glycaemia, there was a downward trend, indicating that the patients perceived fewer episodes of extreme blood glucose. The DTSQs item score for perceived frequency of hyperglycaemia reduced from 4.1 to $1.9(\mathrm{p}<0.05)$ while that for hypoglycaemia reduced from 2.2 to $1.5(\mathrm{p}=0.079)$.

\subsection{Glycaemic Control}

At the start of the study, the average HbA1c level in the cohort was $10.2 \%( \pm 2.2 \%)$. By the first follow-up (12 weeks), the HbA1c had reduced markedly to $7.4 \%( \pm 1.3)$ and further to $7.0 \%( \pm 1.0)(\mathrm{p}<0.05)$ by the end of the study (Figure 1(a)). About half (48.7\%) of the patients with this therapy had achieved HbAlc levels $\leq 7 \%$. A similar effect was observed on the FBG levels which dropped from $10.9( \pm 4.1) \mathrm{mmol} / \mathrm{L}$ at baseline to $6.8( \pm 2.3)$ at 12 weeks and further down to $6.4( \pm 1.8) \mathrm{mmol} / \mathrm{L}$ by the end of the study (Figure 1(b)). About one-fourth (26.0\%) of the study patients achieved an FBG level of $<5.6 \mathrm{mmol} / \mathrm{L}$. At the end of 24 weeks, the study patients were taking an average of 1.6 OADs. A total of $12 \%(n=5)$ had stopped OAD therapy, while the ones on 3 OADs had dropped to $7 \%(\mathrm{n}=3)$.

\subsection{Hypoglycemia Events and Other Adverse Reactions}

A total of 9 (22.0\%) patients who were on glargine plus OAD reported at least one hypoglycemia event. The cohort experienced 16 hypoglycemia events (Grade $1=14$, Grade $2=2$ ) by the time of the first follow-up visit ( 0.8 episodes per year) and this was further halved to 8 (Grade $1=8$; 0.4 episodes per year) by the end of the study (not statistically significant). No severe hypoglycaemia (Grade 3) was reported during the study. Additionally, there were no nocturnal hypoglycemia events reported. Other adverse events reported were mostly minor and none of these were judged to be treatment-related. No serious adverse event was reported.

\subsection{Body Weight}

There was modest weight gain from $65.5( \pm 11.5) \mathrm{kg}$ at baseline to $67.6( \pm 11.6) \mathrm{kg}$ by the end of the study, which did not reach statistical significance.

\subsection{Insulin Dosing}

Starting dose of glargine at recruitment was based individually as per clinical judgement of each doctor and altered as per the patients' needs during the study. In $32 \%$ of the patients $(n=13)$, insulin glargine was administered before bedtime while for the rest of the patients, glargine was administered in the morning. The insulin glargine dose increased during the 24 weeks of the study from a mean (+SD) daily starting dose of $10.6+3.5 \mathrm{IU}$

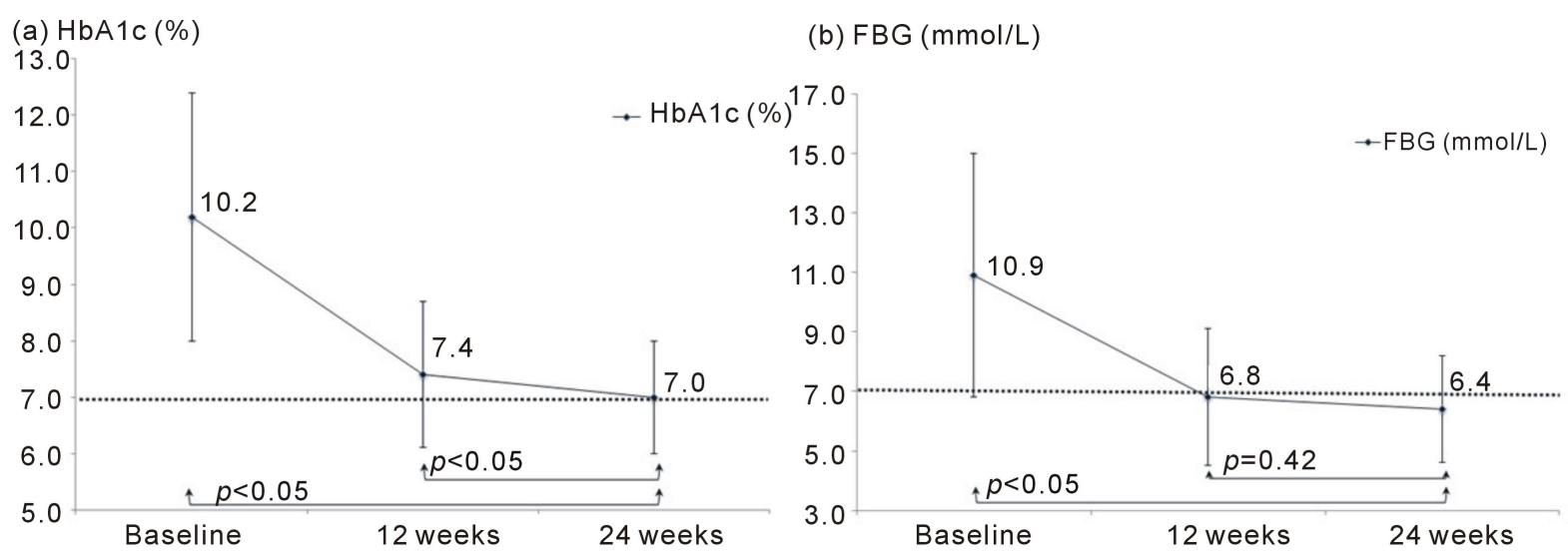

Figure 1. (a) Mean HbA1c value at baseline (recruitment) visit, and at the two follow-up visits at $12( \pm 4)$ and 24 ( \pm 4$)$ weeks after initiation of glargine therapy; (b) Mean FBG value at baseline (recruitment) visit, and at the two follow-up visits at 12 $( \pm 4)$ and $24( \pm 4)$ weeks after initiation of glargine therapy. 
to $17.0+9.1 \mathrm{IU}$ at the end of the study.

\section{Discussion}

Disease progression in diabetes eventually leads to the requirement for exogenously administered insulin to achieve glycaemic control [6]. However, due to various factors that contribute to the patients' "psychological resistance"-fear of needles and concerns about weight gain and hypoglycaemia-insulin use can be hampered or delayed, resulting in unchecked progression of diabetic complications [10] [11]. It is therefore critical to evaluate satisfaction of treatment regimens from the patient's perspective to ensure a positive impact on compliance and adherence.

The Glargine Registry on Treatment Satisfaction, conducted in Hong Kong, evaluated change in patient perception after addition of insulin glargine to OAD regimen in 41 patients with poorly controlled T2DM and no previous treatment with insulin. Furthermore, the registry also assessed the treatment-related effectiveness in terms of achieving glycaemic control and the tolerability in terms of incidence of hypoglycaemia with insulin glargine. In our study, the addition of insulin glargine to OAD therapy in diabetes management improved patient perception on treatment satisfaction and resulted in recommended glycaemic control without any severe sideeffects.

Our study demonstrated an improved DTSQs score over a period of 6 months from the start of glargine therapy to the end of the study. The DTSQs was designed to identify not only the perception of usage (satisfaction, convenience, flexibility and understanding) but also patients' willingness to continue with insulin glargine and recommend the same treatment to other diabetic patients. In addition, the DTSQs also measures patients' perceptions of unacceptably high and low blood glucose-hyperglycaemia and hypoglycaemia. The most pronounced change in DTSQs score was on patient perception of hyperglycaemia with a mean change of $-2.3( \pm 2.4)$ units on a 6 to 0 scale $(\mathrm{p}<0.05)$ between baseline and final follow-up. This change indicated that patients felt they had better control of their blood glucose levels after starting glargine. The improvement in scores on patients' willingness to continue insulin glargine and their willingness to recommend to others suggested that not only did patients in our study find the process of insulinization with glargine acceptable but they were also favourably predisposed to continuing with glargine as a part of their diabetes therapy. The changes in treatment satisfaction scores reported in our study were higher than those reported by others [17] [20]—it could be speculated that this might be due to differences in patient selection criteria and cultural/ethnic differences.

Numerous studies have been published over the last few years regarding the efficacy and utility of glargine over other insulin (NPH, detemir). However, the focus on patient satisfaction and quality of life has only started gaining importance in recent years and numerous questionnaires have been developed to assess various parameters governing these. These methods include the DTSQs [21] [22], Insulin Treatment Satisfaction Questionnaire (ITSQ) [23], the Audit of Diabetes-Dependent Quality of Life (ADDQoL) [24] [25], the Diabetes Symptom Checklist-Revised (DSC-R) [26], the Well-Being Questionnaire (W-BQ), [27] etc. Amongst one of the first, the INSIGHT trial used the DTSQs and ADDQoL scores to conclude that the benefits were significantly better in the glargine-receiving group [17]. A survey in Sweden utilized the DTSQ scores to assess the treatment satisfaction in $>600$ patients with diabetes to conclude that glargine therapy was associated with a high treatment satisfaction and resulted in a decrease in the perceived frequency of hyper/hypo-glycaemia [28]. The first landmark trial to exhaustively study patient perception and quality of life in patients with diabetes on glargine (and determir) was the multination Lantus vs. Levemir Treat-to-Target trial ( $>450$ patients on glargine) [29]. This trial utilized various techniques to analyse the changes in patient perception like the DSC-R, World Health Organization 5 well-being index (WHO-5), Hypoglycaemia Fear Survey (HFS) and two versions of DTSQs. The researchers concluded that encouraging trends were found on fear of hypoglycaemia, diabetes symptom distress and emotional well-being of the patients who had received glargine. Recently, Hajos et al. reported the findings of a study conducted in more than 650 patients with diabetes in the Netherlands utilizing DSC-R, WHO-5 and a modified version of HFS and arrived at a similar conclusion that introduction of glargine in diabetes therapy was associated with improved quality of life [30]. Our study served to provide support to these findings and extended them for the first time (to the best of our knowledge) to a cohort of Chinese T2DM patients in Hong Kong.

Our study also served to recapitulate the synergistic effects of insulin glargine and OAD on achieving glycaemic control. The mean HbA1c level in our study patients was reduced from $10.2 \%$ at baseline to $7.0 \%$ by the end of the study $(\mathrm{p}<0.05)$. Similarly, FBG levels also went down. In addition, the number of OADs that were required to lower the glucose level declined over the course of the study. Overall, about half (48.7\%) of the pa- 
tients had achieved HbA1c levels $<7.0 \%$. Despite the small sample size of our study, the percentage of patients reaching the HbA1c goal of less than $7 \%$ was similar to other well-designed, large scale, international studies such as Treat-to-Target [14], LANMET [16], APOLLO [31] and LAPTOP [32]. All these studies demonstrated that adding insulin glargine was effective in helping half of the patients with uncontrolled T2 DM (HbA1c > 7.5\%) on one or two OADs with no prior experience of insulin to achieve the HbA1c goal.

Physicians have been observed to have a propensity to under dose long-acting insulin analogues for better safety results with a relatively low incidence of hypoglycaemia in patients taking these analogues, especially those with T2DM [33]. Meta-analysis of a few large-scale studies concluded that hypoglycemia events were much reduced in patients receiving glargine in comparison with those on NPH [34] and the safety profile of glargine and detemir was comparable [29]. Glargine was also well-tolerated in this study. A total of 9 (22.0\%) patients reported at least one hypoglycemia event, but the number of hypoglycemia events per patient-years showed a tendency to decrease by half from 16 ( 0.8 episodes per patient-year) at first follow-up to 8 ( 0.4 episodes per patient-year) by the end of the study (statistically not significant). Moreover, none of the patients experienced severe (Grade 3) hypoglycaemia at any time while on glargine. The total number of hypoglycemia episodes-per-patient year in this study was 0.8, which compared favourably with the 6.7 hypoglycemia episodes-per-patient year reported in the landmark LEAD (LANTUS Evaluation in Asian Diabetics) study [35]. This indicated that dose-adjustment and customization based on patient response can help in alleviating the risk of hypoglycaemia. Many other studies including LAPTOP, APOLLO and AT.LANTUS, have also suggested that a glargine-plus-OADs regimen was associated with better glycaemic control and low risk of hypoglycaemia [31] [32] [36]-[40].

Another major concern for the patient taking insulin is weight gain. The average weight gain of our study patients was only $2.1 \mathrm{~kg}$ and did not reach statistical significance despite a major improvement in glycosylated haemoglobin of $3.2 \%$ by the end of the study. This may partly be attributed to the small sample size and inter-ethnic difference, and to the fact that our participants have a lower BMI than their Caucasian counterparts.

The reported study does have limitations. The major short-coming of this study was the small number of patients recruited. The recruitment did not meet the targeted sample size. A significant number of patients were lost to follow-up and it is possible that these patients might have had a less positive experience with glargine, which resulted in their dropping out. However, we did not find any significant differences in baseline characteristics between those who were lost to follow-up and those who completed the study. Second, it was a non-interventional and observational registry. Also, all our patients received insulin glargine and this prevented any comparison with other treatment modalities. Although we managed to show a significant improvement in DTSQs scores, the degree of improvement can be subject to selection bias. Lastly, this study only lasted for 24 weeks and it is always possible that treatment satisfaction might change over time. However, previous studies showed that once patients received insulin, they found that injection insulin was not as distressed as they have anticipated.

\section{Conclusion}

Our study showed that the addition of the insulin glargine to the OAD regimen in patients with poorly controlled T2DM, not only helped in achieving good glycaemic control, but also had a positive impact on the treatment satisfaction and the patients' anxiety over the hypoglycaemia and the weight gain. These findings should help alleviate concerns among patients and physicians that the early insulinization in T2DM management will have a negative effect on patients' satisfaction with the insulin treatment.

\section{Acknowledgements}

This study was funded by Sanofi-Aventis (Hong Kong) Ltd. The authors had access to all data and were responsible for preparing the manuscript for publication. The authors thank Wilson Ngai from Sanofi-Aventis (Hong Kong) Ltd., Satyendra Shenoy and Anahita Gouri from Sanofi (India) for their assistance in preparing this manuscript.

DTSQs ${ }^{\oplus}$ Clare Bradley at www.healthpsychologyresearch.com

\section{References}

[1] Davidson, J.A. (2004) Treatment of the Patient with Diabetes, Importance of Maintaining Target HbA(1c) Levels. 
Current Medical Research and Opinion, 20, 1919-1927. http://dx.doi.org/10.1185/030079904X6291

[2] American Diabetes Association (2006) Standards of Medical Care in Diabetes_2006. Diabetes Care, 29, S4-S42.

[3] Unnikrishnan, A.G., Wangnoo, S.K., Joshi, S.R., et al. (2012) Physician Perceptions and Practices in Management of Diabetes in India, Results from the IMPROVE Control Program. Indian Journal of Endocrinology and Metabolism, 16, S428-S429.

[4] Eliasson, B., Cederholm, J., Nilsson, P. and Gudbjornsdottir, S. (2005) The Gap between Guidelines and Reality, Type 2 Diabetes in a National Diabetes Register 1996-2003. Diabetic Medicine, 22, 1420-1426. http://dx.doi.org/10.1111/j.1464-5491.2005.01648.x

[5] Liberopoulos, E.N., Tsouli, S., Mikhailidis, D.P. and Elisaf, M.S. (2006) Preventing Type 2 Diabetes in High Risk Patients, an Overview of Lifestyle and Pharmacological Measures. Current Drug Targets, 7, 211-228. http://dx.doi.org/10.2174/138945006775515419

[6] Turner, R.C., Cull, C.A., Frighi, V. and Holman, R.R. (1999) Glycemic Control with Diet, Sulfonylurea, Metformin, or Insulin in Patients with Type 2 Diabetes Mellitus, Progressive Requirement for Multiple Therapies (UKPDS 49). UK Prospective Diabetes Study (UKPDS) Group. Journal of the American Medical Association, 281, 2005-2012. http://dx.doi.org/10.1001/jama.281.21.2005

[7] Hirsch, I.B. (2005) Insulin Analogues. The New England Journal of Medicine, 352, 174-183. http://dx.doi.org/10.1056/NEJMra040832

[8] Pearson, J. and Powers, M.A. (2006) Systematically Initiating Insulin, the Staged Diabetes Management Approach. The Diabetes Educator, 32, 19S-28S. http://dx.doi.org/10.1177/0145721705285640

[9] Polonsky, W.H., Fisher, L., Guzman, S., Villa-Caballero, L. and Edelman, S.V. (2005) Psychological Insulin Resistance in Patients with Type 2 Diabetes, the Scope of the Problem. Diabetes Care, 28, 2543-2545. http://dx.doi.org/10.2337/diacare.28.10.2543

[10] Peyrot, M., Rubin, R.R., Lauritzen, T., et al. (2005) Resistance to Insulin Therapy among Patients and Providers, Results of the Cross-National Diabetes Attitudes, Wishes, and Needs (DAWN) Study. Diabetes Care, 28, 2673-2679. http://dx.doi.org/10.2337/diacare.28.11.2673

[11] Hayes, R.P., Fitzgerald, J.T. and Jacober, S.J. (2008) Primary Care Physician Beliefs about Insulin Initiation in Patients with Type 2 Diabetes. International Journal of Clinical Practice, 62, 860-868. http://dx.doi.org/10.1111/j.1742-1241.2008.01742.x

[12] Lepore, M., Pampanelli, S., Fanelli, C., Porcellati, F., Bartocci, L., Di Vincenzo, A., et al. (2000) Pharmacokinetics and Pharmacodynamics of Subcutaneous Injection of Long-Acting Human Insulin Analog Glargine, NPH Insulin, and Ultralente Human Insulin and Continuous Subcutaneous Infusion of Insulin Lispro. Diabetes, 49, 2142-2148. http://dx.doi.org/10.2337/diabetes.49.12.2142

[13] HOE.901/2004 Study Investigators Group (2003) Safety and Efficacy of Insulin Glargine (HOE 901) versus NPH Insulin in Combination with Oral Treatment in Type 2 Diabetic Patients. Diabetic Medicine, 20, 545-551.

[14] Riddle, M.C., Rosenstock, J. and Gerich, J. (2003) The Treat-to-Target Trial, Randomized Addition of Glargine or Human NPH Insulin to Oral Therapy of Type 2 Diabetic Patients. Diabetes Care, 26, 3080-3086. http://dx.doi.org/10.2337/diacare.26.11.3080

[15] Rosenstock, J., Schwartz, S.L., Clark Jr., C.M., Park, G.D., Donley, D.W. and Edwards, M.B. (2001) Basal Insulin Therapy in Type 2 Diabetes, 28-Week Comparison of Insulin Glargine (HOE 901) and NPH Insulin. Diabetes Care, 24, 631-636. http://dx.doi.org/10.2337/diacare.24.4.631

[16] Yki-Jarvinen, H., Kauppinen-Makelin, R., Tiikkainen, M., Vähätalo, M., Virtamo, H., Nikkilä, K., et al. (2006) Insulin Glargine or NPH Combined with Metformin in Type 2 Diabetes: The LANMET Study. Diabetologia, 49, 442-451. http://dx.doi.org/10.1007/s00125-005-0132-0

[17] Houlden, R., Ross, S., Harris, S., Yale, J.F., Sauriol, L. and Gerstein, H.C. (2007) Treatment Satisfaction and Quality of Life Using an Early Insulinization Strategy with Insulin Glargine Compared to an Adjusted Oral Therapy in the Management of Type 2 Diabetes, the Canadian Insight Study. Diabetes Research and Clinical Practice, 78, $254-358$. http://dx.doi.org/10.1016/j.diabres.2007.03.021

[18] Holman, R.R., Thorne, K.I., Farmer, A.J., Davies, M.J., Keenan, J.F., Paul, S., et al. (2007) Addition of Biphasic, Prandial, or Basal Insulin to Oral Therapy in Type 2 Diabetes. The New England Journal of Medicine, 357, 1716-1730. http://dx.doi.org/10.1056/NEJMoa075392

[19] Rosenstock, J., Sugimoto, D., Strange, P., Stewart, J.A., Soltes-Rak, E., Dailey, G., et al. (2006) Triple Therapy in Type 2 Diabetes, Insulin Glargine or Rosiglitazone Added to Combination Therapy of Sulfonylurea Plus Metformin in Insulin-Naïve Patients. Diabetes Care, 29, 554-559. http://dx.doi.org/10.2337/diacare.29.03.06.dc05-0695

[20] Ringborg, A., Cropet, C., Jönsson, B., Gagliardino, J.J., Ramachandran, A. and Lindgren, P. (2009) Resource Use Associated with Type 2 Diabetes in Asia, Latin America, the Middle East and Africa, Results from the International Diabetes Management Practices Study (IDMPS). International Journal of Clinical Practice, 63, 997-1007. 
http://dx.doi.org/10.1111/j.1742-1241.2009.02098.x

[21] Bradley, C. and Lewis, K.S. (1990) Measures of Psychological Well-Being and Treatment Satisfaction Developed from the Responses of People with Tablet-Treated Diabetes. Diabetic Medicine, 7, 445-451. http://dx.doi.org/10.1111/j.1464-5491.1990.tb01421.x

[22] Bradley, C. The Diabetes Treatment Satisfaction Questionnaire, DTSQ. eHopadagtpmidrapC.

[23] Anderson, R.T., Skovlund, S.E., Marrero, D., Levine, D.W., Meadows, K., Brod, M., et al. (2004) Development and Validation of the Insulin Treatment Satisfaction Questionnaire. Clinical Therapeutics, 26, 565-578. http://dx.doi.org/10.1016/S0149-2918(04)90059-8

[24] Bradley, C., Todd, C., Gorton, T., Symonds, E., Martin, A. and Plowright, R. (1999) The Development of an Individualized Questionnaire Measure of Perceived Impact of Diabetes on Quality of Life: The ADDQoL. Quality of Life Research, 8, 79-91. http://dx.doi.org/10.1023/A:1026485130100

[25] Wee, H.L., Tan, C.E., Goh, S.Y. and Li, S.C. (2006) Usefulness of the Audit of Diabetes-Dependent Quality-of-Life (ADDQoL) Questionnaire in Patients with Diabetes in a Multi-Ethnic Asian Country. Pharmacoeconomics, 24, 673682. http://dx.doi.org/10.2165/00019053-200624070-00006

[26] Grootenhuis, P.A., Snoek, F.J., Heine, R.J. and Bouter, L.M. (1994) Development of a Type 2 Diabetes Symptom Checklist: A Measure of Symptom Severity. Diabetic Medicine, 11, 253-261. http://dx.doi.org/10.1111/j.1464-5491.1994.tb00268.x

[27] Pouwer, F., Snoek, F.J., van der Ploeg, H.M., Ader, H.J. and Heine, R.J. (2000) The Well-Being Questionnaire, Evidence for a Three-Factor Structure with 12 Items (W-BQ12). Psychological Medicine, 30, 455-462. http://dx.doi.org/10.1017/S0033291700001719

[28] Gershater, M.A., Frid, A. and Apelqvist, J. (2009) Treatment Satisfaction with Insulin Glargine in Patients with Diabetes Mellitus in a University Hospital Clinic in Sweden. European Diabetes Nursing, 6, 17-22. http://dx.doi.org/10.1002/edn.127

[29] Swinnen, S.G., Dain, M.P., Aronson, R., Davies, M., Gerstein, H.C., Pfeiffer, A.F., et al. (2010) A 24-Week, Randomized, Treat-to-Target Trial Comparing Initiation of Insulin Glargine Once-Daily with Insulin Detemir Twice-Daily in Patients with Type 2 Diabetes Inadequately Controlled on Oral Glucose-Lowering Drugs. Diabetes Care, 33, 1176 1178. http://dx.doi.org/10.2337/dc09-2294

[30] Hajos, T.R., Pouwer, F., de Grooth, R., Holleman, F., Twisk, J.W.R., Diamant, M., et al. (2012) The Longitudinal Association between Glycaemic Control and Health-Related Quality of Life Following Insulin Therapy Optimisation in Type 2 Diabetes Patients. A Prospective Observational Study in Secondary Care. Quality of Life Research, 21, 13591365. http://dx.doi.org/10.1007/s11136-011-0051-0

[31] Bretzel, R.G., Nuber, U., Landgraf, W., Owens, D.R., Bradley, C. and Linn, T. (2008) Once-Daily Basal Insulin Glargine versus Thrice-Daily Prandial Insulin Lispro in People with Type 2 Diabetes on Oral Hypoglycaemic Agents (APOLLO), an Open Randomised Controlled Trial. The Lancet, 371, 1073-1084. http://dx.doi.org/10.1016/S0140-6736(08)60485-7

[32] Janka, H.U., Plewe, G., Riddle, M.C., Kliebe-Frisch, C., Schweitzer, M.A. and Yki-Järvinen, H. (2005) Comparison of Basal Insulin Added to Oral Agents versus Twice-Daily Premixed Insulin as Initial Insulin Therapy for Type 2 Diabetes. Diabetes Care, 28, 254-259. http://dx.doi.org/10.2337/diacare.28.2.254

[33] Little, S., Shaw, J. and Home, P. (2011) Hypoglycemia Rates with Basal Insulin Analogs. Diabetes Technology \& Therapeutics, 13, S53-S64. http://dx.doi.org/10.1089/dia.2011.0022

[34] Mullins, P., Sharplin, P., Yki-Jarvinen, H., Riddle, M.C. and Haring, H.U. (2007) Negative Binomial Meta-Regression Analysis of Combined Glycosylated Hemoglobin and Hypoglycemia Outcomes across Eleven Phase III and IV Studies of Insulin Glargine Compared with Neutral Protamine Hagedorn Insulin in Type 1 and Type 2 Diabetes Mellitus. Clinical Therapeutics, 29, 1607-1619. http://dx.doi.org/10.1016/j.clinthera.2007.08.020

[35] Pan, C.Y., Sinnassamy, P., Chung, K.D. and Kim, K.W. (2007) Glargine versus NPH Insulin Therapy in Asian Type 2 Diabetes Patients. Diabetes Research and Clinical Practice, 76, 111-118. http://dx.doi.org/10.1016/j.diabres.2006.08.012

[36] Blicklé, J.F., Hancu, N., Piletic, M., Profozic, V., Shestakova, M., Dain, M.P., et al. (2009) Insulin Glargine Provides Greater Improvements in Glycaemic Control vs. Intensifying Lifestyle Management for People with Type 2 Diabetes Treated with OADs and 7-8\% A1c Levels. The TULIP Study. Diabetes, Obesity and Metabolism, 11, 379-386. http://dx.doi.org/10.1111/j.1463-1326.2008.00980.x

[37] Schiel, R. and Müller, U.A. (2007) Efficacy and Treatment Satisfaction of Once-Daily Insulin Glargine plus One or Two Oral Antidiabetic Agents versus Continuing Premixed Human Insulin in Patients with Type 2 Diabetes Previously on Long-Term Conventional Insulin Therapy: The Switch Pilot Study. Experimental and Clinical Endocrinology \& Diabetes, 115, 627-633. http://dx.doi.org/10.1055/s-2007-984445

[38] Schreiber, S.A. and Haak, T. (2007) Insulin Glargine Benefits Patients with Type 2 Diabetes Inadequately Controlled 
on Oral Antidiabetic Treatment, an Observational Study of Everyday Practice in 12,216 Patients. Diabetes, Obesity \& Metabolism, 9, 31-38. http://dx.doi.org/10.1111/j.1463-1326.2006.00593.x

[39] Tamemoto, H., Ikoma, A., Saitoh, T., Ishikawa, S.E. and Kawakami, M. (2007) Comparison of Once-Daily Glargine Plus Sulfonylurea with Twice-Daily 70/30 Aspart Premix in Insulin-Naïve Japanese Patients with Diabetes. Diabetes Technology \& Therapeutics, 9, 246-253. Http://Dx.Doi.Org/10.1089/Dia.2006.0016

[40] Davies, M., Lavalle-González, F., Storms, F. and Gomis, R. (2008) Initiation of Insulin Glargine Therapy in Type 2 Diabetes Subjects Suboptimally Controlled on Oral Antidiabetic Agents: Results from the AT.LANTUS Trial. Diabetes, Obesity and Metabolism, 10, 387-399. http://dx.doi.org/10.1111/j.1463-1326.2008.00873.x 
Scientific Research Publishing (SCIRP) is one of the largest Open Access journal publishers. It is currently publishing more than 200 open access, online, peer-reviewed journals covering a wide range of academic disciplines. SCIRP serves the worldwide academic communities and contributes to the progress and application of science with its publication.

Other selected journals from SCIRP are listed as below. Submit your manuscript to us via either submit@scirp.org or Online Submission Portal.
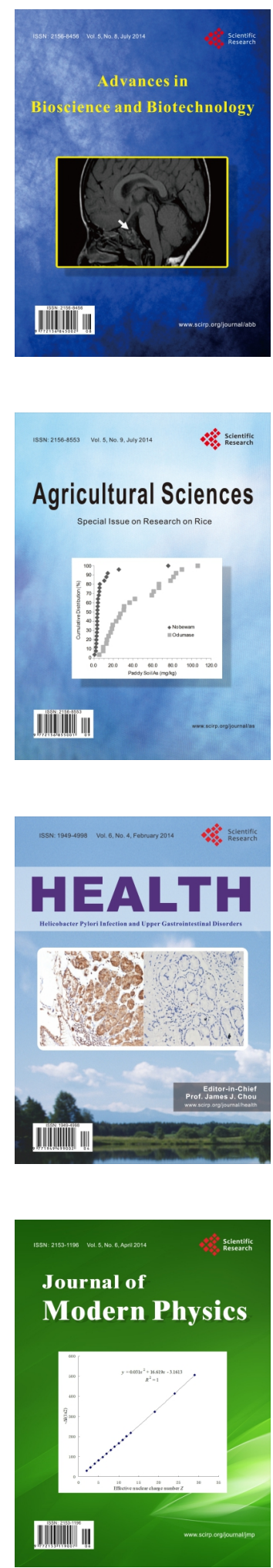
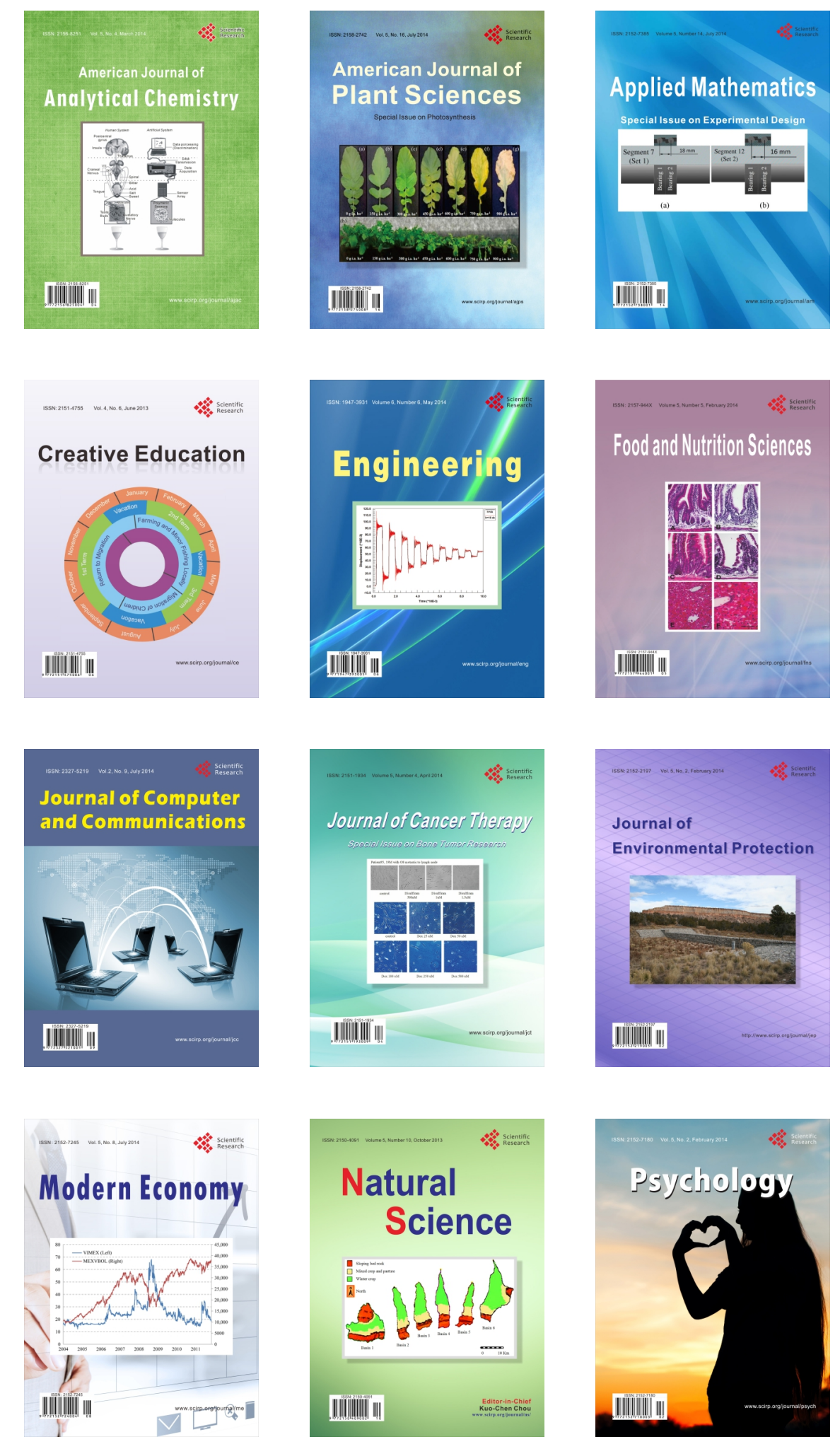